\title{
The Rare Thoracic Tumor, Askin Tumors 7 Cases Report
}

\author{
Mountassir Moujahid1*, Tarik Ziadi², Ahmed Rhari², Karim Nador1', Issam Serghini ${ }^{3}$, \\ Moulay Hassan Tahiri ${ }^{1}$ \\ ${ }^{1}$ Department of General Surgery Service, 5th Military Hospital, Guelmim, Morocco \\ ${ }^{2}$ Department of Radiology Service, 5th Military Hospital, Guelmim, Morocco \\ ${ }^{3}$ Department of Reanimation Service, 5th Military Hospital, Guelmim, Morocco \\ Email: ${ }^{*}$ m.moujahid@gmx.fr
}

Received 13 March 2014; revised 13 April 2014; accepted 20 April 2014

Copyright (C) 2014 by authors and Scientific Research Publishing Inc.

This work is licensed under the Creative Commons Attribution International License (CC BY).

http://creativecommons.org/licenses/by/4.0/

(c) (i) Open Access

\section{Abstract}

The Askin tumour is a highly malignant rare tumour with small cells, pertaining to the group of the primitive neuroectodermal tumours. It develops with the costs of the soft parts of the thoracic wall and it's characterized by extra and endothoracic fast extension. We report seven cases colliged in our service by specifying the role of the imagery in the diagnosis but especially the assessment of extension of these tumours.

\section{Keywords}

\section{Askin Tumour, Neuroectodermal Tumours, CT Scan, MRI}

\section{Introduction}

The Askin tumor is a clinico-pathological entity described in 1979 by Askin and Rosai: rare tumor with small round cells, of high wickedness, developed in soft tissues of the thoraco-lung region, which belongs to the family of the sarcomas of Ewing and the PNET (peripheral neuro ectodermal tumors), who (which) the histogenesis remains uncertain. It would develop from the intercostal nerves and meets especially at the child and the young adult. The objective of this work is to report seven cases collaged in our service.

\section{Observations}

We report 7 cases of Askin tumor, counted in our service in six years, 2 men and 5 women, from 15 to 51 years

*Corresponding author. 
old. In every case it was practiced the standard radiography, a thoracic scanning and an anatomo-pathological confirmation was obtained by draining trans-parietal biopsy under Scan control.

\section{Results (Table)}

\begin{tabular}{|c|c|c|c|c|}
\hline CAS & Age/Sex & Symptômes & Cliché thoracique & T.D.M. \\
\hline 1 & $23 / F$ & $\begin{array}{l}\text { Thoracic pain } \\
\text { Tangible mass }\end{array}$ & $\begin{array}{l}\text { Parietal opacity } \\
\text { Costal Lyse }\end{array}$ & $\begin{array}{l}\text { Mass of } 13 \mathrm{~cm} \\
\text { extension endoextrathoracic }\end{array}$ \\
\hline 2 & $22 / \mathrm{F}$ & Thoracic pain dyspnoea & $\begin{array}{l}\text { Parietal opacity } \\
\text { Costal Lyse }\end{array}$ & $\begin{array}{l}\text { Mass of } 7 \mathrm{~cm} \\
\text { Osseous Lyse }\end{array}$ \\
\hline 3 & $48 / \mathrm{F}$ & Thoracic pain & Pleural effusion & $\begin{array}{c}\text { Mass of } 12 \mathrm{~cm} \\
\text { Diaphragmatic extension }\end{array}$ \\
\hline 4 & $51 / \mathrm{M}$ & Thoracic pain & Pleural effusion & $\begin{array}{c}\text { Mass of } 5 \mathrm{~cm} \text {-Osseous Lyse } \\
\text { Endothoracic extension }\end{array}$ \\
\hline 5 & $36 / F$ & Thoracic pain & Pleural effusion & $\begin{array}{l}\text { Mass of } 6 \mathrm{~cm} \text {-osseous Lyse } \\
\text { Diaphragmatic extension }\end{array}$ \\
\hline 6 & $15 / F$ & Thoracic pain & Parietal opacity & $\begin{array}{c}\text { Mass of } 3 \mathrm{~cm} \\
\text { Lung metastases }\end{array}$ \\
\hline 7 & 20/M & Tangible mass & Pleural effusion & $\begin{array}{c}\text { Mass of } 10 \mathrm{~cm} \\
\text { Diaphragmatic extension }\end{array}$ \\
\hline
\end{tabular}

The signs of appeal are represented in every case by thoracic pains, dyspnoea or by the appearance of parietal mass in two cases. The general state of patients was good. The pleuro-lung exam found a matt effect of the base compared to the mass, the peripheral ganglionic areas did not objective any ganglion.

The thoracic standard radiography and costal grill showed a pleural effusion in 4 cases, an opacity of parietal look in 3 cases and a costal lyse in 2 cases. The thoracic Scan with injection of iodine found a parietal mass of heterogeneous tissular density with zones of necrosis in every case (Figure 1), associated with a pleural infringement in 5 cases (Figure 2), and a costal lyse in 4 cases (Figure 3).

The extension of the tumor in the neighboring lung parenchyma is observed in 2 cases (Figure 1 and Figure 2) and the diaphragmatic invasion in 3 cases (Figure 2). The lung metastases are noted in one case (Figure 4).

\section{Discussion}

The Askin tumor was described the first time by Askin and Rosai in 1979 [1], for a long time considered as a particular entity. However the cyto genetics and the molecular biology, allowed including it with the sarcoma of Ewing and the neuro epithelioma within a single entity under the term of primitive neuro-ectodermal tumors (PNET).

Its histogenesis is uncertain and would result from the migration of cells from the neural crest during the embryonic life [2]. This type of tumor is diagnosed most of the time during the second decade by the life and prevails in the female genital organ (75\%) [1] [3].

The most frequent clinical presentation is the one of a generally voluminous thoraco-lung mass with fast growth with most of the time thoracic pains, respiratory symptoms to type of dyspnoea connected to a hemorrhagic pleurisy even a pericardial infringement. Sometimes, it is revealed by regional ganglionic metastasis or at a distance [5] (lung, osseous, hepatic or Suprarenal gland).

The radiological aspect of the Askin tumor is not specific: on the standard radiographies, it is in the form of a parietal opacity of a party or a whole hemi thorax, sometimes associated with a pleural effusion or with a costal lyse.

The interest and the progress represented by the Scan and especially the MRI allow a precise study of the anatomical reports, an evaluation of the extension, the definition of the operability and the choice of the surgical gesture after biopsy. The scanning specifies the parietal starting point of the mass which is generally heteroge-neous with a central necrosis and sometimes hemorrhagic zones. It allows specifying the extra but especially endo-thoracic extension by showing a pleural invasion with associated effusion, an diaphragmatic in 


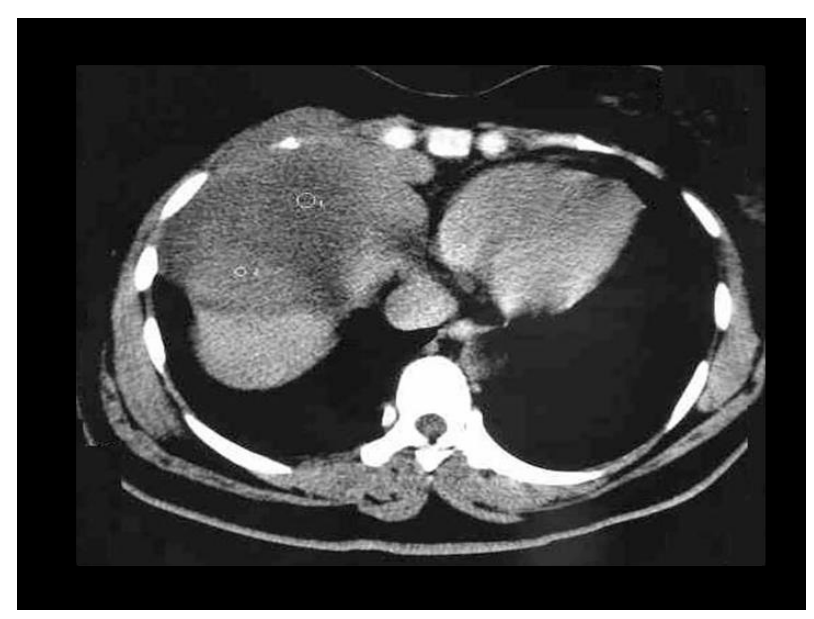

Figure 1. Thoracic scan. Heterogeneous parietal mass.

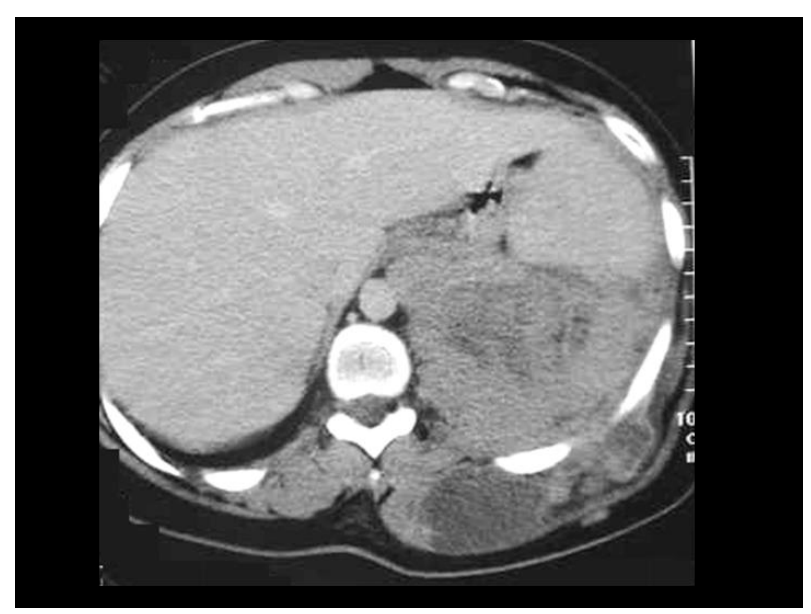

Figure 2. Thoracic scan. Thoraco-abdominal parietal mass with diaphragmatic extension.

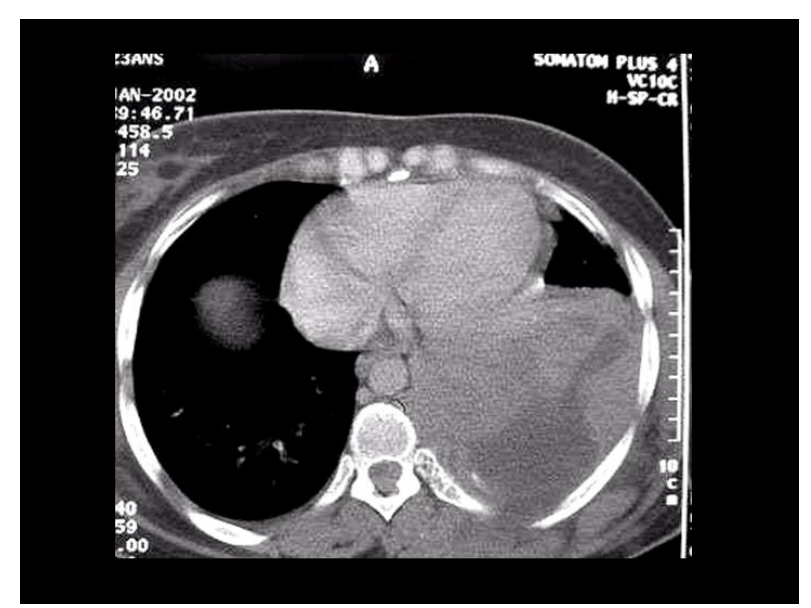

Figure 3. Thoracic scan. Left basal parietal mass with costal and reached pericardial lyse.

fringement, in particular for the thoraco-abdominal low llocalizations, as well as a costal osseous lyse, or vertebral in case of posterior localization, even a mediastinum extension , in particular with a pericardiac infringement. 


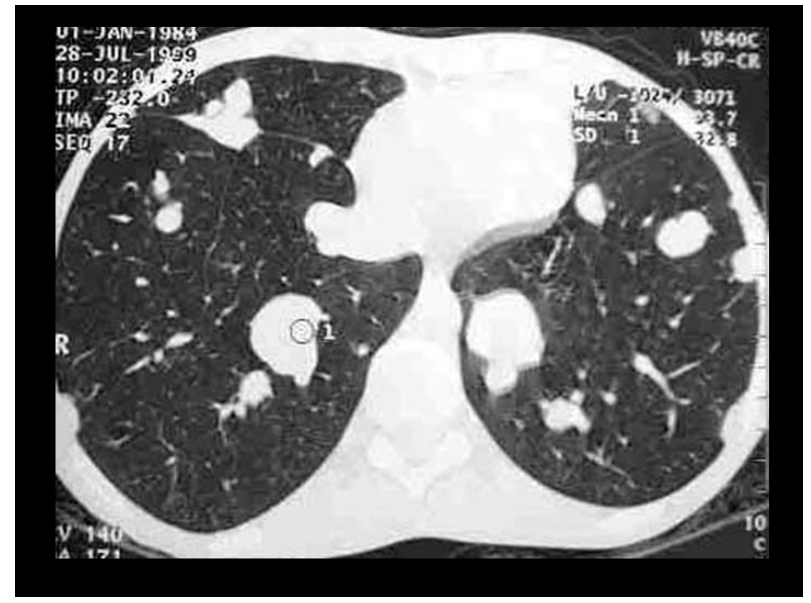

Figure 4. Thoracic scan in window parenchyma. Lung metastases of Askin tumor.

The magnetic resonance imaging (MRI) allows a more precise evaluation of the extension extra-thoracic mild parts, and of the degree of mediastinal-pleural endo thoracic invasion [5] [6]. In the apical localizations, it allows to look for an infringement of the brachial plexus, or a possible medullar compression in case of vertebral infringement [7] [8].

The Scan and the MRI are complementary in fact and allow an optimal analysis of the tumoral extension. Indeed, if the MRI gives more precise information onto the invasion of soft tissues of the thoracic wall, the Scan also allows studying the lung parenchyma in search of small lung metastases [2]. Besides, these examinations allow directing the biopsy for the histological study.

Certainly the imaging has an essential place, but it becomes integrated into an approach which contains a histopathologique time with immunomarquage, as well as a possible cyto genetics study.

On the anatomic-pathological plan, the Askin tumor appears, in a macroscopic manner, in the form of an often round or egg-shaped grey-whitish mass with multiple nodules with the presence of zones of necrosis and bleeding. Histologicaly it is turned out that a sarcoma undifferentiated proliferation in small round cells [3] [9] which raises the problem of differential diagnosis with the other PNET (Sarcoma of Ewing, Neuro epithelioma, Neuroblastoma). The recourse to immuno histochimical technic is necessary [10] [11].

The pronostic of the Askin tumor remains dark because of frequency of the local second recurrences and of the remote metastases (lung, bone, liver, suprarenal glands and mediastinal ganglions) which are present at the time of the diagnosis in $10 \%$ of the cases [4] [12]. The average survival does not exceed 8 months whatever is the treatment [13].

On the therapeutic plan, the surgery has to be most carcinological because of the risk of local second recurrence, but also the radiotherapy and the chemotherapy [14].

At present, the treatment of the localized tumors rests on a neo adjuvant chemotherapy followed by a surgical gesture and/or by radiotherapy. In the case of the voluminous tumors, the local control by the surgery seems more effective than the exclusive radiotherapy.

\section{Conclusion}

The Askin tumor which belongs to the group of peripheral neuroectodermal tumors (PNET) is an aggressive and rare tumor of the thoracic wall. Aspects observed in imaging are not specific, but this one allows specifying the size of the tumor, the endo and extra thoracic extension as well as the existence of lung or ganglion metastases. The multidisciplinary coverage is difficult considering its metastatic potential and the frequency of second recurrences.

\section{References}

[1] Askin, F.B., Rosai, J., Sibley, R.K., et al. (1979) Malignant Small Cell of the Thoraco-Pulmonary Region in Childhood. Cancer, 43, 2438-2451. http://dx.doi.org/10.1002/1097-0142(197906)43:6<2438::AID-CNCR2820430640>3.0.CO;2-9 
[2] Burge, H., et al. (1990) MRI of Askin's Tumors Case Report. Chest, 97, 1252-1254. http://dx.doi.org/10.1378/chest.97.5.1252

[3] Fink, I.J., et al. (1985) Malignant Thoraco-Pulmonary Small Cell (Askin) Tumor. American Journal of Roentgenology, 145, 517-520. http://dx.doi.org/10.2214/ajr.145.3.517

[4] Hannat, S., Filaly Ansali, N., El Fakir, Y., et al. (2003) Askin Tumour. La Presse Médicale, 32, 7.

[5] Muran, H.T., et al. (1993) Primitive Neuroectodermal Tumors of the Chest Wall CT and MR Findings. American Journal of Roentgenology, 161, 265-268.

[6] Kabiri, H., et al. (1999) Thoraco-Lung Cunning Malignant Tumor with Small Cells. Revue de Pneumologie Clinique, 55, 21-25.

[7] Ablin, D.S., Azouz, E.M. and Jain, K.A. (1995) Large Intrathoracic Tumors in Children Imaging Finding. American Journal of Roentgenology, 165, 925-934. http://dx.doi.org/10.2214/ajr.165.4.7676994

[8] Winer-Muram, H., Kauffman, W., Gronemeyer, S.A. and Gregory, J.S. (1993) Primitive Neuro-Ectodermal Tumors of the Chest Wall (Askin Tumors). CT and MR Finding. American Journal of Roentgenology, 145, 265-268. http://dx.doi.org/10.2214/ajr.161.2.8392786

[9] Enzinger, F., et al. (1995) Primitive Neuroectodermal Tumors and Related Lesions, Soft Tissus Tumors, Mosby, 929964.

[10] De Alva, E. and Pardo, J. (2001) Ewing Tumors: Tumor Biology and Clinical Applications. International Journal of Surgical Pathology, 9, 7-17. http://dx.doi.org/10.1177/106689690100900104

[11] Ayadi, H. and Ayoub, A.K. (2002) The Askin Tumor about 2 Observations. Revue de Pneumologie Clinique, 58, 347350.

[12] Marina, N.M., Ectubanas, E., Parman, D.M., et al. (1989) Peripheral Primitive Neuroectodermal Tumor in Children: A Review of the Ste Jude Experience and Controversies in Diagnosis and Management. Cancer, 64, 195-196. http://dx.doi.org/10.1002/1097-0142(19891101)64:9<1952::AID-CNCR2820640931>3.0.CO;2-W

[13] Ibarburen, C., Haberman, J.I. and Zarhouni, E.A. (1996) Peripheral Primitive Neuro-Ectodermal Tumors. CT and MRI Evaluation. European Journal of Radiology, 21, 225-232. http://dx.doi.org/10.1016/0720-048X(95)00731-5

[14] Christiansen, S., Semik, M., Dockhorn-Dworniczak, B., Rotker, J., et al. (2000) Diagnosis, Treatment and Outcome of Patients with Askin-Tumor. The Journal of Thoracic and Cardiovascular Surgery, 48, 311-315. http://dx.doi.org/10.1055/s-2000-7874 